\title{
Luminescence-Based Acute Toxicity Bioassay for Heavy Metals Using Insoluble-Fibroin-Film- Immobilized Vibrio fischeri
}

\author{
Yosuke Tabei, Mariko Era, Akane Ogawa and Hiroshi Morita* \\ Faculty of Environmental Engineering, The University of Kitakyushu, \\ 1-1 Hibikino, Wakamatsu-ku, Kitakyushu, Fukuoka 808-0135, Japan
}

(Received July 26, 2011; accepted October 14, 2011)

Key words: Vibrio fischeri, luminescence, fibroin, toxicity assay, biosensor

Luminescent organisms have been widely used to develop toxicity tests. However, bioluminescence-based methods are often nonspecific and unsuitable for storage. In this study, the marine luminescent bacterium Vibrio fischeri was grown in various media. After immobilization on insoluble fibroin film (IFF)-coated tubes, the luminescence intensity was measured. Late-log cultures grown in nutrient broth containing 3 or $5 \%$ $\mathrm{NaCl}$ were immobilized on IFF-coated tubes at high cell density and found to exhibit higher luminescence intensities. Seawater medium cultures in the stationary phase were also effectively immobilized on IFF-coated tubes and emitted high luminescence. Specifically, IFF-immobilized $V$. fischeri cultures in seawater medium maintained their high luminescence emission for 30 days when stored at $-70^{\circ} \mathrm{C}$. In addition, a bioluminescence toxicity assay with various heavy metal solutions was carried out. Almost all the heavy metals tested decreased the luminescence of IFF-immobilized $V$. fischeri. However, the concentrations required for the effective attenuation of the luminescence were relatively high. In contrast, mercury $(\mathrm{Hg}(\mathrm{II}))$ rapidly dampened the luminescence intensity within a very narrow concentration range. Our findings on the emission of high-luminescence signals by IFF-immobilized $V$. fischeri provide a specific and efficient tool to detect low concentrations of $\mathrm{Hg}(\mathrm{II})$ compounds.

\section{Introduction}

Bioluminescence has been observed in various organisms, including insects, shrimps, jellyfish, squids, and microorganisms. ${ }^{(1)}$ There has been considerable interest in developing luminescent biosensors for environmental and biochemical applications.

${ }^{*}$ Corresponding author: e-mail: morita@env.kitakyu-u.ac.jp 
Initially, researchers focused on the use of naturally luminescent microorganisms such as Vibrio fischeri, whose natural metabolism involves luminescence. ${ }^{(2)}$ Bacterial luciferase mediates the oxidation of reduced flavin mononucleotides and long-chain aliphatic aldehydes by oxygen to produce luminescence. ${ }^{(3,4)}$ Many toxic-sensing systems and toxicity detection methods based on the attenuation of luminescence of natural luminescent or genetically modified bacteria have been proposed.(5) Such a whole-cell microbial toxicity test using the naturally luminescent bacterium $V$. fischeri was marketed as the Microtox ${ }^{\circledR}$ assay and has been internationally adopted as a rapid screening test. ${ }^{(6)}$

Whole-cell microbial biosensors have become one of the newest dimensions of molecular tools in environmental monitoring. ${ }^{(7-9)}$ The basis of these microbial biosensors is the proximity between the microorganisms and the transducer. In this context, immobilization technology has played a major role. ${ }^{(10)}$ Moreover, since microbial biosensors require operational stability and long-term usage, the choice of immobilization technique plays an important role in achieving excellent capacity. In most cases, the immobilization is carried out by the adsorption or entrapment of cells into the gels of polymer matrices. ${ }^{(10)}$ In fact, the adsorption technique is one of the simplest methods for microbe immobilization. However, this immobilization method alone generally leads to poor long-term stability because of microbial detachment. On the other hand, immobilization of microbes by entrapment can be achieved by the retention of the cells in a dialysis/filter membrane or in chemical/biological polymers/gels. ${ }^{(10)}$ A major disadvantage of immobilization by entrapment is the additional diffusion resistance offered by the entrapment materials, which results in lower sensitivity and detection limit.

Previously, we demonstrated that insoluble fibroin film (IFF) is a useful biomaterial that can immobilize various microorganisms such as Escherichia coli, Bacillus subtilis, and Staphylococcus aureus. ${ }^{(11)}$ Fibroin is a natural protein produced by the domestic silkworm, Bombyx mori. It has been used as a biomaterial in various forms such as films, ${ }^{(12-14)}$ membranes, ${ }^{(15)}$ gels, ${ }^{(16)}$ sponges, ${ }^{(17)}$ and powders. ${ }^{(18)}$ Since the fibroin film has excellent biocompatibility and bioadsorbability, and a low inflammatory potential, it has also been studied as a scaffold for tissue engineering, ${ }^{(19-21)}$ and a material for enzyme stabilization. ${ }^{(22,23)}$

In this study, we immobilized the luminescent bacterium $V$. fischeri on IFF-coated tubes by adsorption and subsequently measured its luminescence intensity. Furthermore, we applied the immobilized $V$. fischeri in a heavy metal luminescence-based toxicity assay.

\section{Materials and Methods}

\subsection{Bacterial strain and culture conditions}

All media reagents were obtained from Becton, Dickinson, and Co. (Sparks, MD, USA), Kanto Chemical Co., Inc. (Tokyo, Japan), Nacalai Tasque (Kyoto, Japan), and Wako Pure Chemical Industry (Osaka, Japan). V. fischeri (ATCC 49387) was obtained from the American Type Culture Collection and routinely grown in $100 \mathrm{ml}$ of nutrient broth (NB) (Becton, Dickinson, and Co.) supplemented with $3 \% \mathrm{NaCl}$ in 300 -ml flasks, which were agitated on a shaker at $70 \mathrm{rpm}$ at $22^{\circ} \mathrm{C}$. 
For the growth and luminescence measurements, V. fischeri was cultivated at $22^{\circ} \mathrm{C}$ in NB containing 3 or $5 \% \mathrm{NaCl}$, or seawater medium (SWM) for $48 \mathrm{~h}$. SWM was prepared using artificial seawater (ASW; $28.1 \mathrm{~g} / 1 \mathrm{NaCl}, 0.77 \mathrm{~g} / 1 \mathrm{KCl}, 1.21 \mathrm{~g} / 1 \mathrm{CaCl}_{2}, 4.8 \mathrm{~g} / 1$ $\mathrm{MgCl}_{2} \cdot 6 \mathrm{H}_{2} \mathrm{O}, 0.11 \mathrm{~g} / 1 \mathrm{NaHCO}_{3}$, and $\left.3.5 \mathrm{~g} / 1 \mathrm{MgSO}_{4} \cdot 7 \mathrm{H}_{2} \mathrm{O}\right)$ containing $10 \mathrm{~g} / \mathrm{l}$ beef extract and $10 \mathrm{~g} / \mathrm{l}$ of Bacto-peptone. Bacterial proliferation was monitored by measuring the increase in optical density of the culture suspension at $600 \mathrm{~nm}\left(\mathrm{OD}_{600}\right)$. A Luminescencer PSN luminometer (AB-2200; Atto Corp., Tokyo, Japan) was used to quantify the luminescent signal integrated during a 5 -min period.

\subsection{Preparation of IFF-coated tubes}

IFF-coated tubes were prepared in accordance with the methods described by Tabei et al. ${ }^{(1)}$ In brief, cocoons of $B$. mori were boiled in a $0.5 \% \mathrm{Na}_{2} \mathrm{CO}_{3}$ solution and then rinsed with deionized water. The extracted silk fibroin was dissolved in a $50 \% \mathrm{CaCl}_{2}$ solution. This solution was dialyzed against deionized water for 2 days to remove the salt. Glycerol was added to the $6.5 \mathrm{mg} / \mathrm{ml}$ fibroin solution to a final concentration of $0.5 \%$. IFF-coated tubes were then prepared by casting $50 \mu \mathrm{l}$ of the solution onto the bottom of glass tubes (Thermo Fisher Scientific Inc., Massachusetts, USA) and drying at $30^{\circ} \mathrm{C}$ and $70 \%$ relative humidity. IFFs were prepared by casting the solution onto smooth polypropylene plates and drying them under the same conditions.

\subsection{Immobilization of $\mathrm{V}$. fischeri on IFF-coated tubes}

$V$. fischeri cells were precultured in NB containing 3 or $5 \% \mathrm{NaCl}$, or $\mathrm{SWM}$ at 22 ${ }^{\circ} \mathrm{C}$ to early-log, mid-log, late-log, or stationary phase. Three hundred microliters of the bacterial cultures were diluted in $2.0 \mathrm{ml}$ of the appropriate medium and transferred to IFF-coated or glass tubes, which were incubated at $22^{\circ} \mathrm{C}$ for $0.5,3$, and $6 \mathrm{~h}$. After incubation, the tubes were rinsed 3 times with sterilized water containing $3 \% \mathrm{NaCl}$ to remove nonimmobilized bacteria, and stored at room temperature (RT) or $-70^{\circ} \mathrm{C}$ for 30 days. Thereafter, the luminescent signals of $V$. fischeri immobilized on the IFF-coated or glass tubes were measured with a Luminescencer PSN luminometer.

\subsection{Field emission scanning electron microscopy (FE-SEM)}

For FE-SEM observation, $V$. fischeri cells were immobilized on an IFF $(180 \times 180$ $\left.\mathrm{mm}^{2}\right)$ or cover glass $\left(180 \times 180 \mathrm{~mm}^{2}\right)$ following the methods described above. After 0.5 , 3 , or $6 \mathrm{~h}$ of incubation, the cells immobilized on the IFFs and cover glasses were fixed with $2.5 \%$ glutaraldehyde in $0.1 \mathrm{M}$ phosphate-buffered saline (PBS) (pH 7.3) for $2 \mathrm{~h}$ at $\mathrm{RT}$, and then washed thrice with 0.1 M PBS (pH 7.3). The samples were subjected to dehydration with a graded series of ethanol solution, dried, and coated with platinum (E-1030; Hitachi, Tokyo, Japan) or gold (E-1010; Hitachi, Tokyo, Japan) using an ion sputter apparatus. Finally, the samples were examined by FE-SEM (S-5200; Hitachi, Tokyo, Japan).

\subsection{Toxicity assay for heavy metals}

The chemicals, namely, chromium chloride $\left(\mathrm{CrCl}_{3} \cdot 6 \mathrm{H}_{2} \mathrm{O}\right)$, iron sulfate $\left(\mathrm{FeSO}_{4} \cdot 7 \mathrm{H}_{2} \mathrm{O}\right)$, nickel chloride $\left(\mathrm{NiCl}_{2}\right)$, copper chloride $(\mathrm{CuCl})$, zinc chloride $\left(\mathrm{ZnCl}_{2}\right)$, sodium arsenate $\left(\mathrm{NaHAsO}_{4} \cdot 7 \mathrm{H}_{2} \mathrm{O}\right)$, sodium arsenite $\left(\mathrm{NaAsO}_{2}\right)$, cadmium chloride $\left(\mathrm{CdCl}_{2}\right)$, mercuric 
chloride $\left(\mathrm{HgCl}_{2}\right)$, and lead nitrate $\left(\mathrm{Pb}\left(\mathrm{NO}_{3}\right)_{2}\right)$, were purchased from Wako Pure Chemical Industry.

The analyzed concentration ranges used for the different metal solutions were as follows: $\mathrm{Cr}$ (III) $(16,50,80$, and $160 \mathrm{ppm}) ; \mathrm{Fe}(\mathrm{II})(100,1,000$, and 10,000 ppm); $\mathrm{Ni}(\mathrm{II})$ $(16,5,000$, and 10,000 ppm); $\mathrm{Cu}(\mathrm{I})(25,80$, and $160 \mathrm{ppm}) ; \mathrm{Zn}(\mathrm{II})(8,50$, and $500 \mathrm{ppm})$; $\operatorname{As}(\mathrm{V})(1,2,5,10,25$, and $50 \mathrm{ppm}) ; \mathrm{As}(\mathrm{III})(10,50$, and $100 \mathrm{ppm}) ; \mathrm{Cd}(\mathrm{II})(10,100$, and $1,000) ; \mathrm{Hg}(\mathrm{II})(0.05,0.1,0.25$, and $0.5 \mathrm{ppm})$; and $\mathrm{Pb}(\mathrm{II})(4,50$, and $500 \mathrm{ppm})$. Since $V$. fischeri requires $\mathrm{NaCl}$ for its optimal activity, all the metal solutions were supplemented with $3 \% \mathrm{NaCl}$. One hundred microliters of the metal solutions were added to the IFFimmobilized $V$. fischeri and incubated for 5 or $15 \mathrm{~min}$, after which the luminescence intensity was measured with a Luminescencer PSN luminometer.

\section{Results}

\subsection{Growth and luminescence of $\mathrm{V}$. fischeri in various media}

As an initial experiment, we examined the growth and luminescence of $V$. fischeri in various media at $22^{\circ} \mathrm{C}$ (Fig. 1). V. fischeri actively grew in $\mathrm{NB}$ containing $3 \% \mathrm{NaCl}$ (hereafter referred to as $3 \% \mathrm{NB}$ ), reaching an $\mathrm{OD}_{600}$ of approximately 3.5 after $48 \mathrm{~h}$ (Fig.

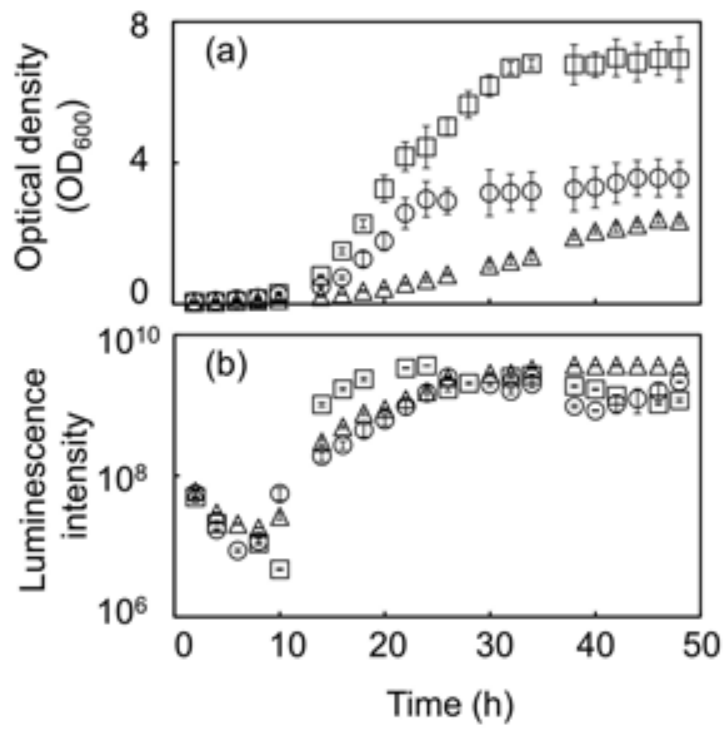

Fig. 1. Growth profiles (a) and luminescence intensities (b) of $V$. fischeri in NB containing 3 or $5 \% \mathrm{NaCl}$ (circles or triangles, respectively), or SWM (squares) over a 48-h period. Growth was measured using a spectrophotometer set at $600 \mathrm{~nm}$. Luminescence was measured using a Luminescencer PSN luminometer. Data represent the average values from experiments performed in triplicate. The error bars represent the standard deviation. 
1(a)). The luminescence intensity of $V$. fischeri decreased during the early-log phase and then increased as the culture entered the late-log phase (Fig. 1(b)). In the presence of $5 \% \mathrm{NaCl}$ (hereafter referred to as $5 \% \mathrm{NB}$ ), reduced growth rates and cell densities were observed. The cell densities in $5 \% \mathrm{NB}$ reached an $\mathrm{OD}_{600}$ of approximately 2.5 (Fig. 1(a)). On the other hand, in 5\% NB, high luminescence intensities were obtained at the stationary phase. These intensities were approximately 20 -fold higher than those obtained in 3\% NB (Fig.1(b)). Similarly, $V$. fischeri actively grew in SWM, with cell densities reaching $\mathrm{OD}_{600}$ of approximately 7.0 (Fig. 1(a)). The maximum luminescence intensity was obtained at the late-log phase (Fig. 1(b)).

\subsection{Luminescence intensity of $\mathrm{V}$. fischeri immobilized on IFF-coated tubes}

Before immobilization onto the IFF-coated tubes, $V$. fischeri cells were precultured in $3 \% \mathrm{NB}, 5 \% \mathrm{NB}$, or SWM and grown to early-log, mid-log, late-log, or stationary phase. The cells at each growth phase were immobilized on the IFF-coated or glass tubes for 0.5 , 3, or 6 h. The luminescence intensities were subsequently measured (Fig. 2).

The luminescence intensities of early-log-phase cultures grown in $3 \% \mathrm{NB}$ and immobilized on IFF-coated tubes were similar to those of cultures immobilized on glass tubes (Fig. 2(a)). In contrast, the luminescence intensities of late-log-phase cultures were significantly higher on IFF-coated tubes than on glass tubes (Fig. 2(c)). Under the latter conditions, the luminescence intensity of cultures immobilized for $3 \mathrm{~h}$ on the IFF-coated tubes was approximately 45 -fold higher than that of cultures immobilized on the glass tubes. High luminescence intensities of IFF-immobilized cultures were also observed at the mid-log and stationary phases; however, the intensities were lower than those observed at the late-log phase (Figs. 2(b) and 2(d)).

When grown in 5\% NB, IFF-immobilized $V$. fischeri exhibited high luminescence intensities during all the growth phases (Figs. 2(e)-2(h)). Unlike that in the case under the $3 \%$ NB condition, the luminescence intensities of early-log-phase cultures were significantly different between IFF-coated and glass tubes (Fig. 2(e)). Specifically, latelog-phase cultures immobilized for $3 \mathrm{~h}$ on IFF-coated tubes exhibited high luminescence intensity, its intensity being approximately 400 -fold higher than that on the glass tubes (Fig. $2(\mathrm{~g}))$.

When SWM cultures at mid-log, late-log, and stationary phase were used for immobilization, significant differences in the luminescence intensities were observed between the IFF-coated tubes and the glass tubes (Fig. 2(i)-2(1)). Although no significant differences were observed between the 2 types of tubes when SWM cultures at the early$\log$ phase were immobilized for $0.5 \mathrm{~h}$, differences emerged when they were immobilized for $3 \mathrm{~h}$ or longer (Fig. 2(i)). Stationary-phase cultures immobilized on IFF-coated tubes for $3 \mathrm{~h}$ exhibited high luminescence intensity, which was approximately 100 -fold higher than that on the glass tubes (Fig. 2(1)).

These results revealed that the highest luminescence intensities are obtained when V. fischeri cells were immobilized onto the IFF-coated tubes compared with onto the glass tubes. Furthermore, these results indicated that late-log-phase cultures in 5\% NB and stationary-phase cultures in SWM provide the best conditions to obtain high luminescence intensities. 


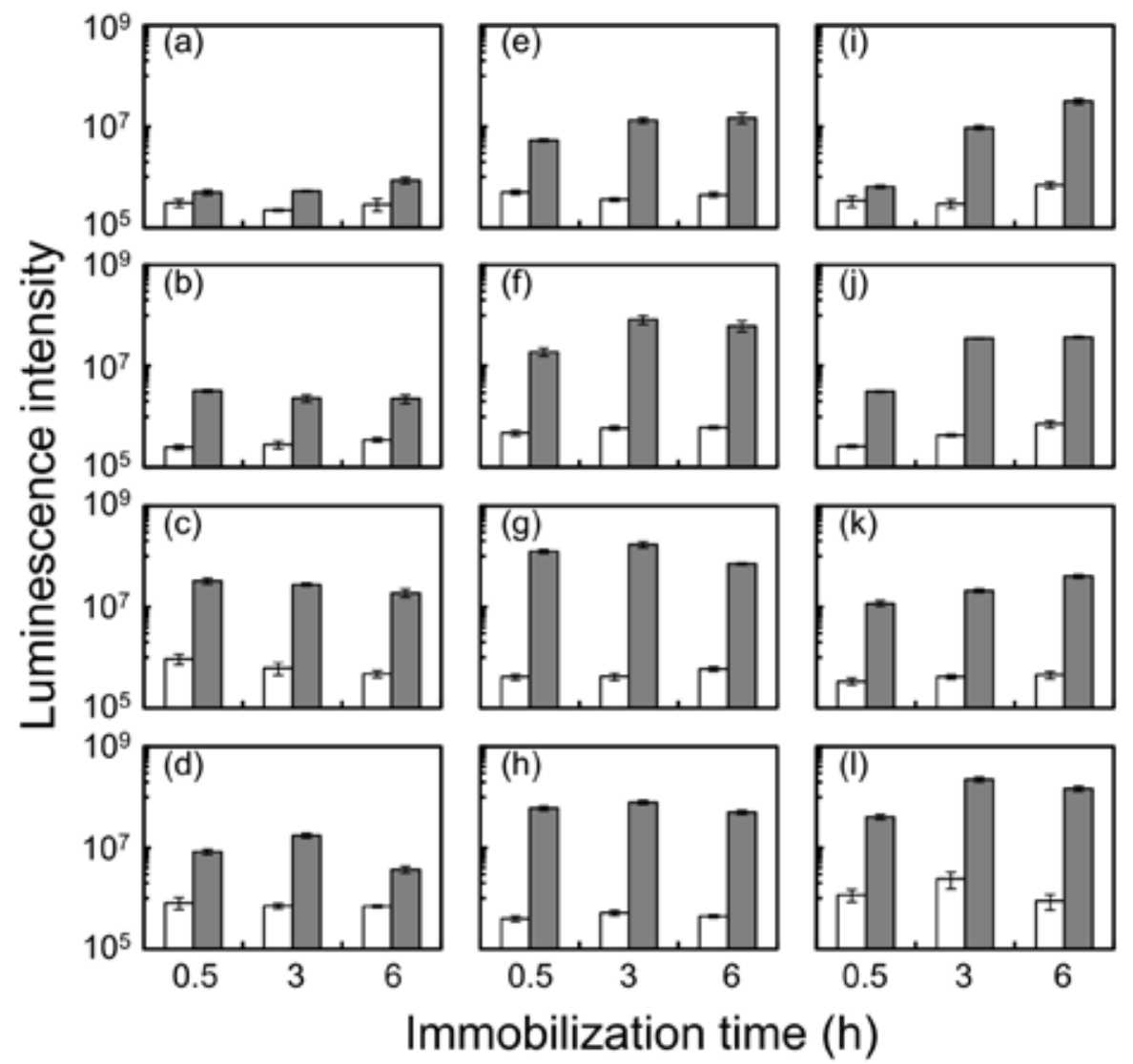

Fig. 2. Luminescence intensity of $V$. fischeri immobilized on glass or IFF-coated tubes in various media. $V$. fischeri cells were precultured in $\mathrm{NB}$ containing $3 \% \mathrm{NaCl}(\mathrm{a}-\mathrm{d}), \mathrm{NB}$ containing $5 \% \mathrm{NaCl}(\mathrm{e}-$ h), or SWM (i-l) at various growth phases. The cells at early-log (a, e, and i), mid-log (b, f, and j), late-log (c, g, and k), and stationary (d, h, and l) phase were immobilized on the glass tube or the IFF-coated tubes for $0.5,3$, and $6 \mathrm{~h}$ at $22^{\circ} \mathrm{C}$. The white bars indicate the luminescence intensity of $V$. fischeri immobilized on glass tubes, whereas the gray bars indicate that of $V$. fischeri immobilized on IFF-coated tubes. Experiments were performed in triplicate, and the error bars represent the standard deviation.

\subsection{Microscopic analysis of IFF-immobilized V. fischeri}

To verify whether the higher luminescence intensities exhibited by IFF-immobilized $V$. fischeri were caused by the adsorption of cells at high density, we investigated the immobilization patterns of $V$. fischeri on the IFF by FE-SEM (Fig. 3). FE-SEM observations revealed significant differences between the IFF and the glass. When $3 \%$ NB cultures at late-log phase were immobilized onto the glass, the cells were not adsorbed at high cell density during the following $6 \mathrm{~h}$ (Figs. 3(a)-3(c)). In contrast, they 



Fig. 3. Electron microscopy images of $V$. fischeri immobilized on a cover glass (a-c) or IFF (d-1). $V$. fischeri were precultured in $\mathrm{NB}$ containing $3 \% \mathrm{NaCl}(\mathrm{a}-\mathrm{f})$ or $\mathrm{NB}$ containing $5 \% \mathrm{NaCl}(\mathrm{g}-\mathrm{i})$ at the late-log phase, and in SWM (j-1) at the stationary phase. The cells were immobilized on the cover glass or the IFF for 0.5 (a, d, g, and j), 3 (b, e, h, and k), and 6 (c, f, i, and l) h at $22^{\circ} \mathrm{C}$. The white scale bar corresponds to $100 \mu \mathrm{m}$ in all the images.

were immobilized onto the IFF at a high cell density (Figs. 3(d)-3(f)). The number of adsorbed cells on the IFF increased over $6 \mathrm{~h}$. Similarly, in 5\% NB, the number of cells adsorbed onto the IFF increased over 6 h (Figs. 3(g)-3(i)). Nonetheless, the total number of cells was lower than that in $3 \% \mathrm{NB}$. The SWM cultures at stationary phase were also adsorbed onto the IFF (Figs. 3(j)-3(1)). The number of adsorbed cells in SWM increased over $3 \mathrm{~h}$ (Figs. 3(j) and 3(k)), and was maintained over the following $6 \mathrm{~h}$ (Fig. 3(1)).

These results indicated that $V$. fischeri may be effectively immobilized on IFF-coated tubes using a variety of media, and that immobilization at high cell density is achieved within a period of 3 to $6 \mathrm{~h}$.

\subsection{Effects of storage on the luminescence stability of IFF-immobilized V. fischeri}

Since microbial biosensors require long-term usage to achieve excellent capacity, we investigated the luminescence stability of $V$. fischeri on IFF-coated tubes stored at RT or $-70^{\circ} \mathrm{C}$ (Fig. 4). When IFF-coated tubes immobilized with $5 \% \mathrm{NB}$ cultures were stored at RT, the luminescence intensity was markedly decreased by day 1 , reaching levels that were approximately 100 -fold lower than at the initial time point (day 0 ) 

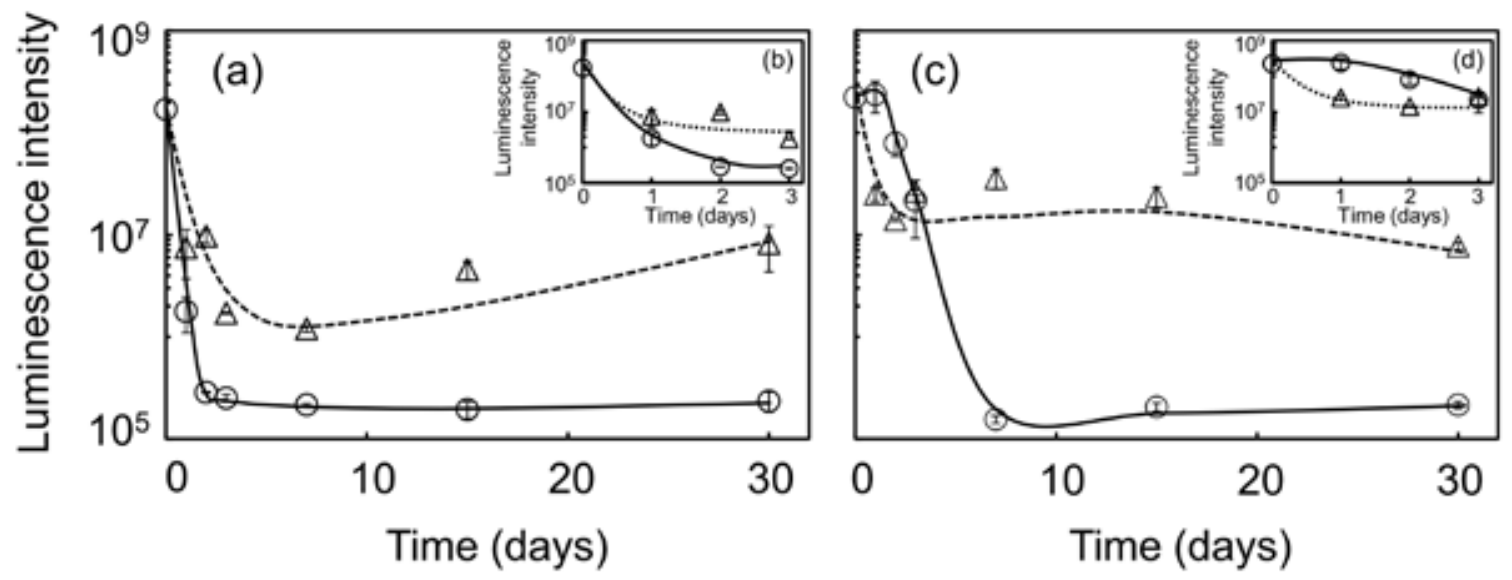

Fig. 4. Effect of storage temperature on the luminescence stability of immobilized $V$. fischeri. The IFF-coated tubes with immobilized cultures grown in $\mathrm{NB}$ containing $5 \% \mathrm{NaCl}(\mathrm{a}$ and $\mathrm{b}$ ) and SWM (c and d) were stored at room temperature (circles and solid line) or $-70^{\circ} \mathrm{C}$ (triangles and dotted line) for 30 days. The insets ( $b$ and d) show the luminescence stability during a short-term period (3 days). Experiments were performed in triplicate, and the error bars represent the standard deviation.

(Figs. 4(a) and 4(b)). The luminescence intensity of IFF-coated tubes stored at RT was almost completely abrogated by the end of day 2 , and did not recover over the following 30 days. Similarly, the luminescence intensity of the IFF-coated tube stored at $-70^{\circ} \mathrm{C}$ decreased over the first 7 days, reaching levels that were approximately 100 -fold lower than those at day 0 . Surprisingly, the decreased luminescence intensity at $-70^{\circ} \mathrm{C}$ was recovered by days 15 and 30. The reason for the latter observation remains unclear.

Similar to the results obtained with the $5 \%$ NB cultures, when the IFF-coated tubes immobilized with SWM cultures were stored at RT, the luminescence intensity decreased over 7 days to levels that were approximately 1,500-fold lower than those at the initial time point (day 0) (Fig. 4(c)). On the other hand, at $-70^{\circ} \mathrm{C}$, the high luminescence intensity persisted for a period of 30 days. Notwithstanding the intense signals, the luminescence intensity at day 1 was approximately tenfold lower than that at day 0 .

Next, we compared the luminescence stability between 5\% NB and SWM cultures immobilized on IFF-coated tubes during a short-term period (3 days) and found that a higher luminescence stability was obtained from SWM cultures than from 5\% NB cultures (Figs. 4(b) and 4(d)). In SWM cultures, interestingly, the luminescence intensity of tubes stored at RT was higher than that of tubes stored at $-70^{\circ} \mathrm{C}$ during a short-term period (Fig. 4(d)). Since the luminescence stability of SWM cultures immobilized on IFF-coated tubes was higher than that of $5 \%$ NB cultures, we used IFF-coated tubes immobilized with SWM cultures for the following toxicity assay. 


\subsection{Application of $\mathrm{V}$. fischeri luminescence for an acute toxicity assay}

We determined the dose-response luminescence curves of $V$. fischeri immobilized on IFF-coated tubes exposed to various concentrations of different metal solutions, namely, $\mathrm{Cr}(\mathrm{III}), \mathrm{Fe}(\mathrm{II}), \mathrm{Ni}(\mathrm{II}), \mathrm{Cu}(\mathrm{I}), \mathrm{Zn}(\mathrm{II}), \mathrm{As}(\mathrm{V}), \mathrm{As}(\mathrm{III}), \mathrm{Cd}(\mathrm{II}), \mathrm{Hg}(\mathrm{II})$, and $\mathrm{Pb}$ (II) (Fig. 5). Decreases in luminescence intensity, in spite of differences in the effective concentration ranges, could be observed when $V$. fischeri cells were exposed to metal solutions for 5 $15 \mathrm{~min}$. Metals interfered with $V$. fischeri luminescence on the IFF-coated tubes in the following order from most to least: $\mathrm{Hg}(\mathrm{II}), \mathrm{As}(\mathrm{V}), \mathrm{Cr}(\mathrm{III}), \mathrm{As}(\mathrm{III}), \mathrm{Cu}(\mathrm{I}), \mathrm{Zn}(\mathrm{II}), \mathrm{Pb}(\mathrm{II})$, $\mathrm{Cd}(\mathrm{II}), \mathrm{Fe}(\mathrm{II})$, and $\mathrm{Ni}(\mathrm{II})$. Under all the tested conditions, the inhibitions of luminescence at $15 \mathrm{~min}$ were higher than those at $5 \mathrm{~min}$.

When comparing the shape of the dose-response curves, it appears that the curves corresponding to $\mathrm{Hg}$ (II) show a very rapid decrease in luminescence intensity within a very narrow concentration range, even after only $5 \mathrm{~min}$ of exposure (Fig. 5(i)). $\mathrm{Hg}$ (II)induced inhibition of $V$. fischeri luminescence occurred at concentrations lower than $0.25 \mathrm{ppm}$. $\mathrm{Cr}(\mathrm{III})(50 \mathrm{ppm})$ and $\mathrm{Cu}(\mathrm{I})(80 \mathrm{ppm})$ also exerted inhibitory effects on $V$. fischeri luminescence, but at concentrations higher than that of $\mathrm{Hg}$ (II) (Figs. 5(a) and 5(d)). When V. fischeri was exposed to arsenic compounds (As(V) and As(III)), the luminescence intensity was also reduced. However, relatively higher concentrations of $\mathrm{As}(\mathrm{V})$ and $\mathrm{As}(\mathrm{III})$ were necessary to achieve significant inhibitions (Figs. 5(f) and $5(\mathrm{~g}))$. Comparison of the toxicity of the arsenic compounds shows that the effective concentration of $\mathrm{As}(\mathrm{V})$ was fourfold lower than that of $\mathrm{As}(\mathrm{III})$. Indeed, approximately $80 \mathrm{ppm}$ of $\mathrm{As}(\mathrm{III})$, but only $20 \mathrm{ppm}$ of $\mathrm{As}(\mathrm{V})$, reduced the luminescence intensity to $10 \%$ or less of the initial luminescence. In contrast, $\mathrm{Ni}(\mathrm{II})$ did not conspicuously affect the luminescence intensity even at high concentrations (Fig. 5(c)). Similarly, V. fischeri luminescence on the IFF-coated tubes was resistant to exposure to $\mathrm{Fe}(\mathrm{II}), \mathrm{Zn}(\mathrm{II}), \mathrm{Cd}(\mathrm{II})$, and $\mathrm{Pb}(\mathrm{II})$ for $15 \mathrm{~min}$ (Figs. 5(b), 5(e), 5(h), and 5(j)). The concentrations of $\mathrm{Fe}(\mathrm{II})$, $\mathrm{Zn}(\mathrm{II}), \mathrm{Cd}(\mathrm{II})$, and $\mathrm{Pb}(\mathrm{II})$ required to reduce the luminescence intensity to $10 \%$ or less of the initial luminescence were approximately 2,000, 200, 900, and $500 \mathrm{ppm}$, respectively.

These results indicate that IFF-immobilized $V$. fischeri can be used to effectively detect low $\mathrm{Hg}$ (II) concentrations (lower than $0.25 \mathrm{ppm}$ ) by monitoring the attenuation of its luminescence intensity. On the other hand, the inhibitory effect of $\mathrm{Cr}(\mathrm{III}), \mathrm{Fe}(\mathrm{II})$, $\mathrm{Ni}(\mathrm{II}), \mathrm{Cu}(\mathrm{I}), \mathrm{Zn}(\mathrm{II}), \mathrm{As}(\mathrm{V}), \mathrm{As}(\mathrm{III}), \mathrm{Cd}(\mathrm{II})$, and $\mathrm{Pb}(\mathrm{II})$ on $V$. fischeri luminescence was not observed at low concentrations.

\section{Discussion}

In this study, we demonstrated that the $V$. fischeri luminescence intensity and the number of cells immobilized on IFF-coated tubes are significantly higher than on other surfaces, namely, glass (Figs. 2 and 3). Specifically, 5\% NB cultures at late-log phase and SWM cultures at stationary phase displayed the highest luminescence intensities (Fig. 2). Moreover, when SWM cultures were immobilized on IFF-coated tubes, the high luminescence intensity was retained for 30 days if stored at $-70^{\circ} \mathrm{C}$ (Fig. 4).

For many decades, $V$. fischeri has been a model organism for studying luminescence and its regulation. The bacteria produce diffusible compounds, known as autoinducers, 

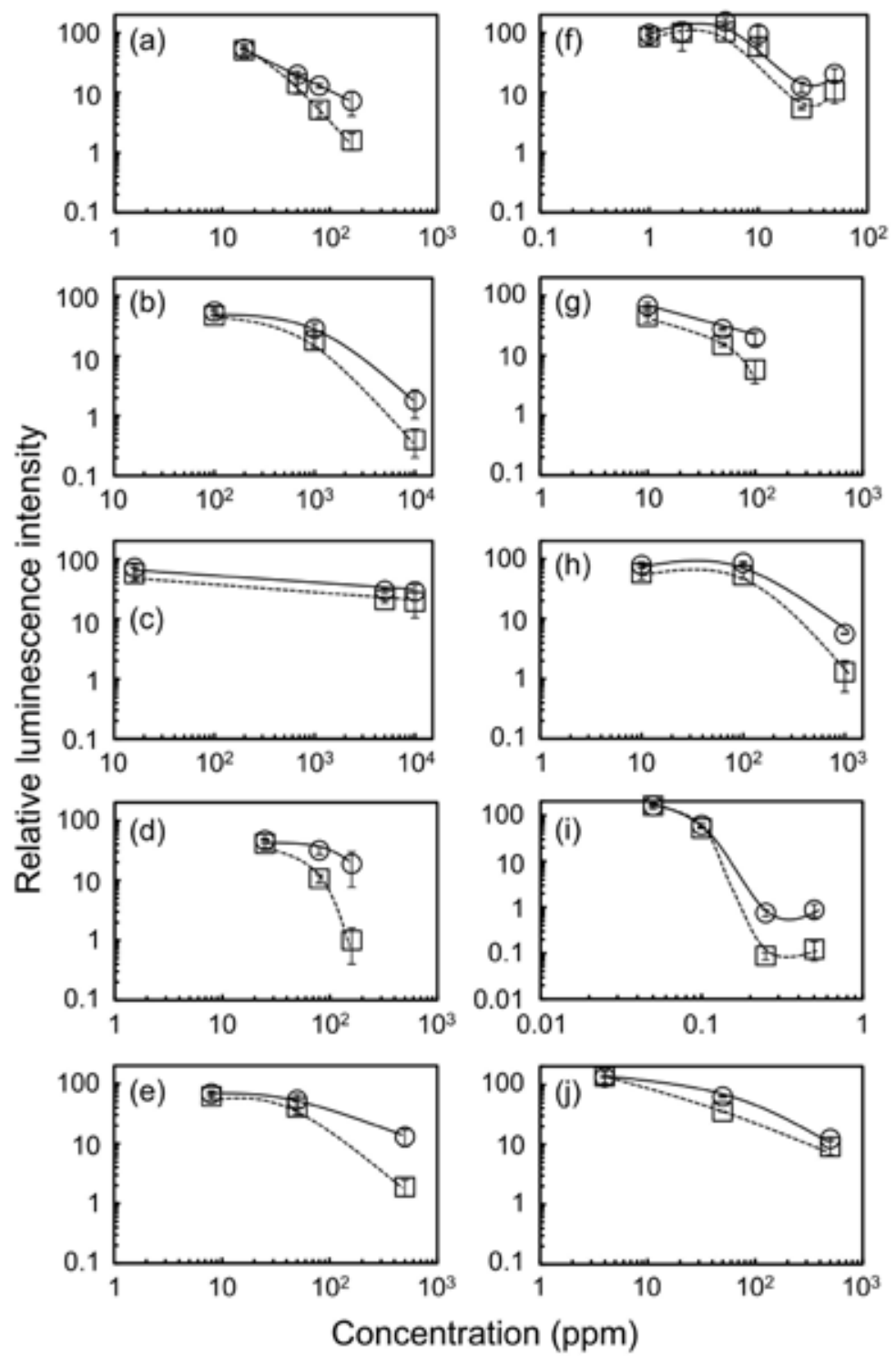

Fig. 5. Application of $V$. fischeri luminescence immobilized on IFF-coated tubes for heavy metal toxicity assay. V. fischeri cells were exposed to $100 \mu \mathrm{l}$ of $\mathrm{Cr}(\mathrm{III})$ (a), $\mathrm{Fe}(\mathrm{II})$ (b), $\mathrm{Ni}(\mathrm{II})$ (c), $\mathrm{Cu}(\mathrm{I})(\mathrm{d}), \mathrm{Zn}(\mathrm{II})(\mathrm{e}), \mathrm{As}(\mathrm{V})$ (f), $\mathrm{As}(\mathrm{III})(\mathrm{g}), \mathrm{Cd}(\mathrm{II})(\mathrm{h}), \mathrm{Hg}(\mathrm{II})(\mathrm{i})$, and $\mathrm{Pb}(\mathrm{II})$ (j) solutions at various concentrations for $5 \mathrm{~min}$ (circles and solid line) and $15 \mathrm{~min}$ (squares and dotted line). The precise concentrations of each metal solution are described in the Materials and Methods section. Experiments were performed in triplicate, and the error bars represent the standard deviation. 
which accumulate in the surrounding environment during growth and subsequently induce bacterial luminescence at high cell density. ${ }^{(24-28)}$ In contrast to the well-known cell-density-dependent luminescence, we have recently discovered cell-densityindependent luminescence in $V$. fischeri under nutrient-starved conditions. ${ }^{(29)}$ Moreover, we demonstrated that this type of luminescence is sulfur-dependent and requires the addition of sulfur compounds. ${ }^{(30)}$ In this study, the luminescence of $V$. fischeri immobilized on IFF was significantly higher than that of $V$. fischeri immobilized on glass (Fig. 2). Previously, Robson indicated that silk fibroin contains a low amount of cysteine/cystine $(0.2 \%) \cdot{ }^{(31)}$ According to this observation, the IFF used in this study contains approximately $13 \mathrm{mg} / \mathrm{l}$ cysteine. Moreover, our previous results demonstrated that sulfur-dependent luminescence was induced even at a low cell density by the addition of $10 \mathrm{mg} / \mathrm{l}$ cysteine or cystine as the sole sulfur source. ${ }^{(30)}$ Although the detailed mechanisms underlying this phenomenon are unclear, the higher luminescence achieved on IFF-coated tubes might be caused by the presence of cysteine or cystine via mechanisms similar to that of sulfur-dependent luminescence.

Luminescence inhibitory assays using $V$. fischeri are sensitive, rapid, cost-effective, and reproducible. ${ }^{(32)}$ Previously, Fulladosa et al. ${ }^{(33)}$ demonstrated that $\mathrm{Cu}(\mathrm{II}), \mathrm{Zn}(\mathrm{II})$, $\mathrm{Hg}(\mathrm{II})$, and $\mathrm{Pb}(\mathrm{II})$ exert an adverse effect on $V$. fischeri luminescence even at low concentrations $(<1 \mathrm{mg} / \mathrm{l})$. The toxicity of $\mathrm{Hg}$ (II) and $\mathrm{Pb}$ (II) can be related to the high affinity of $\mathrm{Hg}(\mathrm{II})$ and $\mathrm{Pb}$ (II) for - $\mathrm{SH}$ groups, such as those present in glutathione and cysteine, which are critically involved in cellular defense mechanisms. ${ }^{(34,35)}$ Moreover, $\mathrm{Hg}(\mathrm{II})$ acts potently on cell membranes causing alteration in both membrane stability and functions over a narrow range of concentrations. ${ }^{(36)}$ The toxicity of $\mathrm{Cu}(\mathrm{II})$ and $\mathrm{Pb}$ (II) on $V$. fischeri luminescence might be explained by their antibacterial activity that affects the bacteria's enzyme system. ${ }^{(37)}$ In this study, in accordance with previous observations, $\mathrm{Hg}$ (II) rapidly dampened $V$. fischeri luminescence intensity within a very narrow concentration range (Fig. 5(i)). The effective inhibitory $\mathrm{Hg}(\mathrm{II})$ concentration was greater than 100-fold lower than that of any of the other metal compounds tested. Moreover, $\mathrm{Cu}(\mathrm{I}), \mathrm{Zn}(\mathrm{II})$, and $\mathrm{Pb}(\mathrm{II})$ were less toxic than $\mathrm{Hg}(\mathrm{II})$. These results suggest that the inhibition of IFF-immobilized $V$. fischeri luminescence was probably caused by $\mathrm{Hg}(\mathrm{II})-$ induced cell membrane instability and dysfunctions, and not by the inhibition of cellular defense mechanisms or enzymes.

In this study, the inhibitory effects of $\mathrm{Cr}(\mathrm{III}), \mathrm{As}(\mathrm{V}), \mathrm{As}(\mathrm{III})$, and $\mathrm{Cd}(\mathrm{II})$ were lower than that of $\mathrm{Hg}(\mathrm{II})$ (Fig. 5). Previously, Fulladosa et al. ${ }^{(38,39)}$ reported that $V$. fischeri is able to reduce $\mathrm{Cr}(\mathrm{VI})$ to $\mathrm{Cr}(\mathrm{III})$, which is much less toxic, thereby decreasing chromate activity. The low toxicity of arsenic compounds for both luminescence and growth was also previously observed in $V$. fischeri..$^{(38,40)}$ Moreover, Fulladosa et al. ${ }^{(33)}$ demonstrated that $V$. fischeri exhibits a low sensitivity to Cd(II) exposure. The low toxicity of $\mathrm{Cd}(\mathrm{II})$ might result from the presence of exopolysaccharides on the outer layer, which has been found to adsorb and trap Cd(II) compounds. Our results are in accordance with those previous observations that revealed little toxic effect of low concentrations of $\mathrm{Cr}(\mathrm{III})$, $\mathrm{As}(\mathrm{V}), \mathrm{As}(\mathrm{III})$, and $\mathrm{Cd}(\mathrm{II})$ on the decreased V. fischeri luminescence. 


\section{Conclusions}

Bioluminescence inhibition assays have been applied as sensitive and rapid screening tools for measuring the toxicity of various compounds. ${ }^{(6)}$ However, bioluminescence assays have been barely used to detect a particular compound because many toxic compounds interfere with and attenuate the luminescence intensity. In this study, the luminescence of $V$. fischeri immobilized on the IFF-coated tubes was markedly and specifically decreased by exposure to $\mathrm{Hg}$ (II) even at a low concentration $(0.25 \mathrm{ppm})$. In contrast, all the other heavy metal compounds tested, namely, $\mathrm{Cr}(\mathrm{III}), \mathrm{Fe}(\mathrm{II}), \mathrm{Ni}(\mathrm{II})$, $\mathrm{Cu}(\mathrm{I}), \mathrm{Zn}(\mathrm{II}), \mathrm{As}(\mathrm{V}), \mathrm{As}(\mathrm{III}), \mathrm{Cd}(\mathrm{II})$, and $\mathrm{Pb}(\mathrm{II})$, interfered with $V$. fischeri luminescence only at high concentrations. Although further investigation is necessary to improve $\mathrm{Hg}$ (II) sensitivity, our results suggest that application of IFF-immobilized $V$. fischeri will lead to the development of a $\mathrm{Hg}$ (II)-specific and $\mathrm{Hg}$ (II)-sensitive biosensor, which will be able to detect $\mathrm{Hg}(\mathrm{II})$ conveniently and rapidly under environmental conditions.

\section{Acknowledgment}

This work was supported in part by the Regional Innovation Cluster Program of the Ministry of Education, Culture, Sports, Science and Technology (MEXT), Japan.

\section{References}

1 J. Lee: Bioluminescence, The Science of Photobiology, ed. K. C. Smith (Plenum Publishing, New York, 1989) p. 391.

2 K. H. Nealson and J. W. Hastings: Microbiol. Rev. 43 (1979) 496.

3 J. W. Hastings and K. H. Nealson: Ann. Rev. Microbiol. 31 (1977) 549.

4 E. A. Meighen: Microbiol. Rev. 55 (1991) 123.

5 S. Girotti, E. N. Ferri, M. G. Fumo and E. Maiolini: Anal. Chim. Acta 608 (2008) 2.

6 S. M. Steinberg, E. J. Poziomek, W. H. Engelmann and K. R. Rogers: Chemosphere 30 (1995) 2155.

7 S. F. D'Souza: Biosens. Bioelectron. 16 (2001) 337.

8 S. Belkin: Curr. Opin. Microbiol. 6 (2003) 206.

9 Y. Lei, W. Chen and A. Mulchandani: Anal. Chim. Acta 568 (2006) 200.

10 S. F. D’Souza: Appl. Biochem. Biotechnol. 96 (2001) 225.

11 Y. Tabei, K. Tsutsumi, A. Ogawa, M. Era and H. Morita: Sens. Mater. 23 (2011) 195.

12 N. Minoura, S. Aiba, M. Higuchi, Y. Gotoh, M. Tsukada and Y. Imai: Biochem. Biophys. Res. Commun. 208 (1995) 511.

13 C. Acharya, S. K. Ghosh and S. C. Kundu: J. Mater. Sci. Mater. Med. 19 (2008) 2827.

14 J. Kundu, M. Dewan, S. Ghoshal and S. C. Kundu: J. Mater. Sci. Mater. Med. 19 (2008) 2679.

15 N. Minoura, M. Tsukada and M. Nagura: Biomaterials 11 (1990) 430.

16 M. Fini, A. Motta, P. Torricelli, G. Giavaresi, N. N. Aldini, M. Tschon, R. Giardino and C. Migliaresi: Biomaterials 26 (2005) 3527.

17 M. Li, M. Ogiso and N. Minoura: Biomaterials 24 (2003) 357.

18 T. Hino, M. Tanimoto and S. Shimabayashi: J. Colloid Interface Sci. 266 (2003) 68.

19 N. Minoura, S. Aiba, Y. Gotoh, M. Tsukada and Y. Imai: J. Biomed. Mater. Res. 29 (1995) 1215. 
20 K. Inouye, M. Kurokawa, S. Nishikawa and M. Tsukada: J. Biochem. Biophys. Methods 37 (1998) 159.

21 S. Sofia, M. B. McCarthy, G. Gronowicz and D. L. Kaplan: J. Biomed. Mater. Res. 54 (2001) 139.

22 S. Lu, X. Wang, Q. Lu, X. Hu, N. Uppal, F. G. Omenetto and D. L. Kaplan: Biomacromolecules 10 (2009) 1032.

23 Q. Lu, X. Wang, X. Hu, P. Cebe, F. Omenetto and D. L. Kaplan: Macromol. Biosci. 10 (2010) 359.

24 J. Engebrecht and M. Silverman: Proc. Natl. Acad. Sci. U.S.A. 81 (1984) 4154.

25 A. Kuo, N. V. Blough and P. V. Dunlap: J. Bacteriol. 176 (1994) 7558.

26 L. Gilson, A. Kuo and P. V. Dunlap: J. Bacteriol. 177 (1995) 6946.

27 A. Kuo, S. M. Callahan and P. V. Dunlap: J. Bacteriol. 178 (1996) 971.

28 S. M. Callahan and P. V. Dunlap: J. Bacteriol. 182 (2000) 2811.

29 Y. Tabei, M. Era, A. Ogawa and H. Morita: Biosci. Biotechnol. Biochem. 75 (2011) 1073.

30 Y. Tabei, M. Era, A. Ogawa and H. Morita: J. Basic Microbiol. 52 (2012) 216.

31 R. M. Robson: 'Silk: composition, structure and properties.' Fibre Chemistry - Handbook of Fibre Science and Technology, vol. IV, eds. M. Lewin and E. Pearce (Mercel Dekker, New York, 1985) p. 647.

32 S. Parvez, C. Venkataraman and S. Mukherji: Environ. Int. 32 (2006) 265.

33 E. Fulladosa, J. C. Murat, M. Martinez and I. Villaescusa: Chemosphere 60 (2005) 43.

34 C. D. Klaassen, J. Liu and S. Choudhuri: Annu. Rev. Pharmacol. Toxicol. 39 (1999) 267.

35 Y. Gaubin, F. Vaissade, F. Croute, B. Beau, J. P. Soleilhavoup and J. C. Murat: Biochim. Biophys. Acta 1495 (2000) 4.

36 G. Repetto, P. Sanz and M. Repetto: Toxicol. in Vitro 7 (1993) 353.

37 P. Madoni, D. Davoli, G. Gorbi and L. Vescovi: Water Res. 30 (1996) 135.

38 E. Fulladosa, J. C. Murat and I. Villaescusa: Arch. Environ. Contam. Toxicol. 49 (2005) 299.

39 E. Fulladosa, V. Desjardin, J. C. Murat, R. Gourdon and I. Villaescusa: Chemosphere 65 (2006) 644.

40 E. Fulladosa, J. C. Murat, M. Martinez and I. Villaescusa: Arch. Environ. Contam. Toxicol. 46 (2004) 176. 